\title{
Feasibility study of Web-based Instruction Application in Iran's distance education
}

\author{
Farhad Shariati \\ Department of Education and Psychology, University of Payam-e-Noor \\ Khalil Gholami \\ Department of Education, University of Kurdistan, Sanandaj \\ E-mail: farhad.shariati@gmail.com \\ Doi:10.5296/ijld.v3i6.4466 URL: http://dx.doi.org/10.5296/ijld.v3i6.4466
}

\begin{abstract}
This paper addresses the faculty and student perception on web-based instruction in order to explain the nature of learning and instruction in this setting. Using a mixed method approach, the research studied a sample of 62 University Faculty and 163 students in University of Payam-e-noor Kurdistan. The research tools were interview and questionnaire. The results of Exploratory Factor Analysis suggested that five basic components could explain the nature of learning and instruction of web-based instruction in distance education: the lack of authentic learning, autonomy in learning tasks, the weakness of faculty role in instruction, technical skills in web-based instruction and infrastructure and policy-making. These five components could explicate two more fundamental themes: the overall nature of learning and teaching in web-based instruction and web-based obstacles.
\end{abstract}

Keywords: Virtual Education, Web-Based Instruction, Educational Technology, Faculty Perception, Distance, Education

\section{Introduction}

The advent of the knowledge economy and global economic competition, more than ever, results in the need to prioritize educational quality, life-long learning and the provision of equal opportunities for all. Education policymakers widely accept that improved access to information and communication technology (ICT) in education can help individuals to compete in a global economy by creating a skilled work force and facilitating social mobility. Experts also argue that sound ICT policy in education has a multiplier effect throughout the education system, by enhancing learning and providing students with new sets of skills; by reaching students with poor or no access (especially those in rural and remote regions); by facilitating and improving the training of teachers; and by minimizing costs associated with the delivery of instruction. This ultimately results in better overall educational achievement and learning outcomes.(UNESCO 2012)

The use of online learning is increasing in higher education. There are a number of reasons why this is occurring, including its potential to provide flexible access to content and instruction at any time, from any place and cost-effectiveness for institutions of higher education. Online learning can increase the availability of learning experiences for learners who cannot, or who choose not to, attend traditional face-to-face (onsite) offerings, it offers an opportunity to disseminate course content more cost-efficiently, and also enables higher student to faculty ratios while maintaining a level of outcome quality equivalent to face-toface instruction. (Sidney R. Castle, \& Chad J. McGuire 2010). 
The increased involvement of technology in all aspects of our lives places educational institutions under pressure to include these aspects at the heart of their learning. Undoubtedly, the implementation of e-Learning systems in higher education has enabled a dramatic change in teaching and learning practices. The success of e-Learning adoption across an organization depends on several factors, for example, the availability of technology, how instructors are supported in its use, and the integration of technology within the faculty member teaching experience (Muhannad Al-Shboul1 2013).

Virtual universities provide a unique function for today's educational leaders around the world. These cutting-edge universities commonly offer glimpses into the possible future of higher education, while at the same time paving the way(in terms of both policy and implementation) for other universities and colleges. The struggles of today's virtual universities will provide the foundation for institutional (and government) leaders in the future as they weigh the financial and academic options of distance education.(UNESCO 2002)

Web-based learning is a tool for knowledge continuity. It provides more opportunities for instructor-student interaction, increased student's commitment and enhanced teaching and learning environment. WBL facilitates in fulfilling knowledge gaps students discover by providing the resources where students can utilize to satisfy their knowledge hunger. Webbased type of learning can reach out to large numbers of students quickly with information that can be tailored to the needs of the learners. Compared to solely traditional classroom learning, combining multiple learning strategies such as integrating between traditional learning and WBL can improve both students knowledge of the subjects learned and information retention more than $100 \%$ examined students' learning satisfactions in a blended e-learning system environment found that learning climate such as computer self-efficacy significantly affected learning satisfaction and performance. (Saiful Hafizah Jaaman, Rokiah Rozita Ahmad1, \& Azmin Sham Rambely12013).

Whilst traditional teaching methods, such as face-to-face lectures, tutorials, and mentoring, remain dominant in the educational sector, universities are investing heavily in learning technologies, to facilitate improvements with respect to the quality of learning. The implementation of information and communication technology (ICT) as an advanced flexible technology with its unique characteristics is one of the main new investments. However it should be noticed that "despite their potential, telematics applications are not yet regularly used as instructional tools (e.g., in The Netherlands, with one of the world's highest concentrations of Internet users and personal and organisational computer use, a national study has indicated that almost all university students use e-mail and the World Wide Web on a personalbasis, but in general computer use in educational programmes is limited to occasional information searche. While the use of ICT in distance learning for off-campus students is already accepted stated that there is also a trend in higher education to utilise the benefits of e-learning to improve the learning performance of campus-based students. As a resultof this trend, many universities around the world are expanding their investment in ICT.Nevertheless, equipment and connectivity do not guarantee successful or productive ICT use.

We should consider that implementing technology in education is complex, shaped by pedagogical philosophies, curricular requirements, and the proliferation of ICT in society at large. Literature on instructional technology shows that the use of the Internet in education has the potential to motivate students and teachers, increase student participation and interaction in the classroom, and provide students with a more active role in their learning, increased motivation, and increased autonomy in the educational process. While teachers are requested to use the capability of the new high technology to facilitate learning processes, 
students are encouraged to improve their learning through computer and networked-based activities.

In many cases, however, educational institutions do not pay enough attention to the questions of how, what, and why ICT should be implemented. According to ICT implementation often takes place without a theory and many institutions do not spend any resources on trying to understand what kind of changes ICT and computers bring into their system; they just follow the new trend, casting doubt on the success and cost effectiveness of such initiatives. When universities promote ICT use, they need to understand their teachers' and students' attitudes towards its use. Teachers' attitudes are considered as a major predictor of the use of new technologies in instructional settings. An analysis of cross-cultural studies carried out in the 1990s revealed that sometimes changes in attitudes are more important than changes in skills for teachers' advance in technology integration. Therefore, we agree with Cheung and Huang (2005) that only when parties involved in the process of learning are making use of ICT to really benefit students' learning, is IT investment justified in terms of a university's scarce resources. (Hossein Mahdizadeh, Harm Biemans, \& Martin Mulder 2008).

\section{Methodology}

We used a mixed method approach in which quantitative data were more prominent in analyzing and reporting results. Qualitative data were used for basic understanding of research problem, especially for developing questionnaire based on interviews with participants. Such research designs are called "sequential approach" where the data from one phase of the study become a basis for another (Creswell, 2003). Population was the faculty and student of University of Pyam-e-Noor Kurdistan. First, five faculty member were interviewed in order to gain insight into the problem. Second, relying on interviews, we developed a questionnaire and administrated it in the university among 62 faculties and 153 students. The first tool for collecting data was semi-structured interview in which there were some open-ended questions. The general theme of questions was same in all interviews however; the probing questions were asked to conceive interviewees' answers deeply. The theme of questions was based on previous research and according to research objectives. Based on deductive approach, interviews were analyzed. In other words, the research questions were considered as a deductive framework and then the interviews were analyzed in terms of the research questions. Two general themes including several categories were developed in the qualitative data: the nature of learning and teaching in WBI, and challenges and barriers to WBI. The second tool was the questionnaire developed based on the interviews consisting of 20 items. The items of questionnaire were designed in such a way that could address two themes explored in qualitative data analysis. Cronbach $\alpha$ calculated for questionnaire was $71.6 \%$ and it showed a fair reliability. Confirmatory Factor Analysis (CFA) showed extraction of five factors. Goodness of fit was measured for obtained factors. It showed that model enjoyed appropriate goodness for considered items in questionnaire (see detailed information in section of results).

\section{Conclusion and Discussion}

Relying on interviews, results of factor analysis showed that faculty determined five fundamental factors in terms of application WBI in Iran's distance education; lack of authentic learning, self-regulating learning, and faculty'scontrolling role, technical skill of WBI and infrastructure and policy making. The first three component sindicated a basic theme called quality of learning and teaching in WBI. Furthermore, two other components clustered into another central theme called barriers to WBI development. The overall results showed that most of the faculty perceived the quality of WBI as challenging than facilitating, even though the difference was not statistically significant. Regarding to the barriers to WBI in higher education, most of the faculty perceived the level of barriers as minor. Considering the 
association between the mediating variables with both themes, as it can be seen in the figure 1 , there was a significant difference between levels of internet use by faculty in terms of quality of teaching and learning in WBI: the faculty with high level of using internet, perceived WBI less challenging. Also, there was a statistically significant difference among various fields of study in regarding to barriers to WBI development. Other variables showed no significant association with two basic themes. (Khalil Gholami, \& Yaser Sayadi 2012)

Like several other research (Daugherty \& Funke, 1998; Maguire, 2005), this research shows that development of valid and authentic learning in virtual education is a challenge based on faculty's attitudes. Moreover, faculty believes that they are not able to play their role well to control class and students' learning. From one hand, this attitude results from epistemic presumptions of positivism dominating Iran's higher education and on the other hand, faculty adheres to traditional theories of learning (e.g., behaviorism). Based on these presumptions and theories, an authentic knowledge can be acquired with scientific methods, and such knowledge may be found in existing academic textbooks and resources, thus they should be presented face to face by faculty -in order to being able to control class and students' learning. In other words, good knowing and knowledge can be constructed out of learners' mind, therefore; external factors especially teacher is prominent to determine the significant and reliability learning. Another reason that faculty failed to perceive knowledge as authentic in WBI is to hold a praiseworthy attitude towards science and knowledge. Concerning this attitude, good knowledge has been already produced by scientists and scientific methods. University and higher education institutions should preserve structure of science and its production (Balard, 1991; cited in Zarei, 2010).

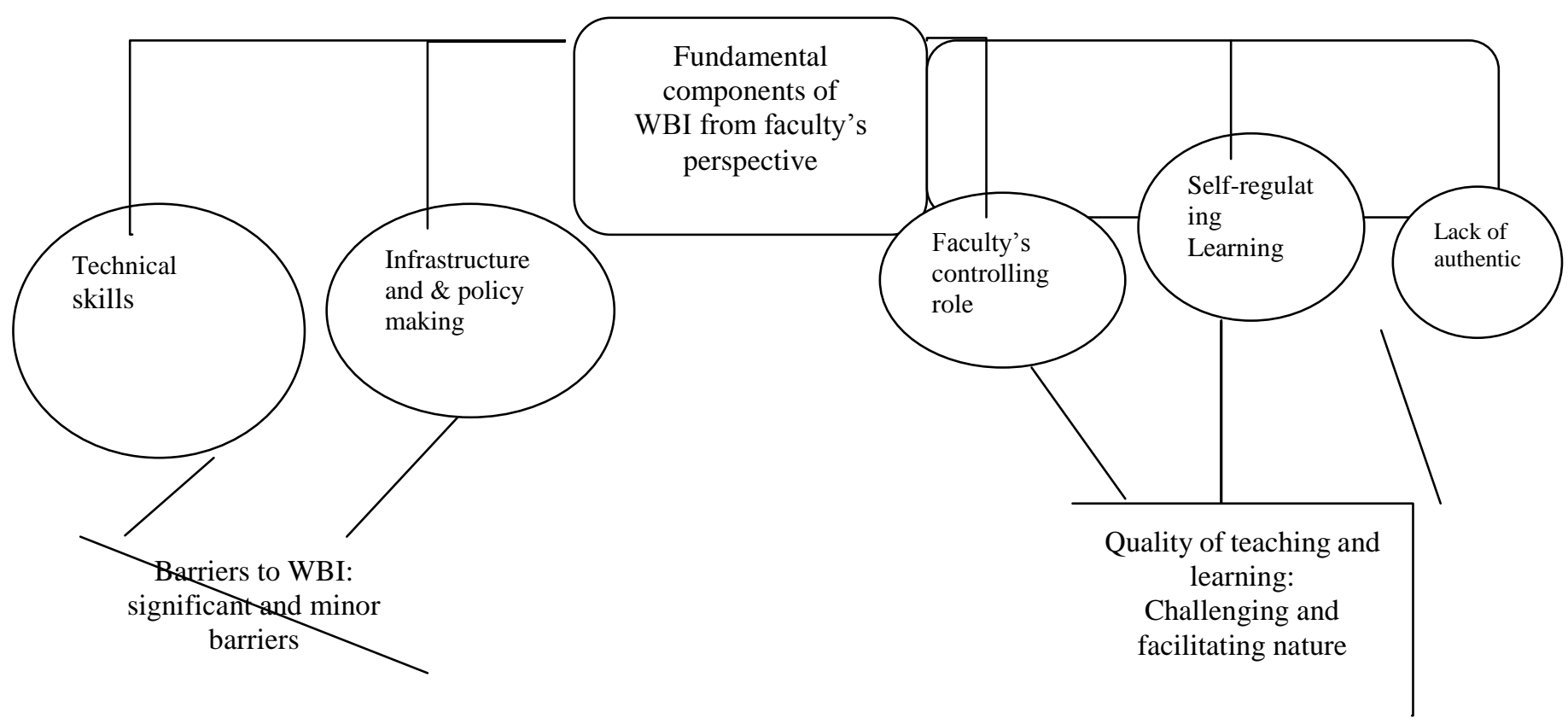

Figure 1. Conceptual framework of virtual education based on faculty's attitudes

Perceiving WBI as challenging, the faculty however believed that WBI is crucial to provide an environment in which students can regulate their learning. Other research (e.g., Bullen, 1999; Keengwe et al., 2009, Mobaraki, 2010) also demonstrates that WBI is an effective approach to develop learning, enrich learning environment and help students to concentrate more on learning task and regulate it based on their own condition and interests. These findings indicate that virtual education like other professional and technological phenomenon has positive and effective properties to develop educational condition in spite of some challenges. A meta-analysis shows that the faculty sometimes conflict in their attitudes towards WBI because 
WBI is quite new to Iran's universities such as university of Kurdistan. Moreover, since there are not appropriate facilities and infrastructures for conducting WBI, it causes confliction in the faculty's attitudes toward WBI. The findings suggested thatmost of the faculty consider the lack of policy making and poor infrastructures as basic barriers to develop virtual education . The lack of faculty's and students' technical skills was the other significant barrier and challenge in Iran's virtual education. These barriers have also been mentioned in other research (e.g., Daugherty \& Funke, 1998; Zarei, 2010).

It is considerable that regardless of the field of study and departments in University of pyame-noor Kurdistan, most of the faculty stated that WBI can be a facilitating tool for teaching and learning in Iran's distance education. It confirms that faculty's general attitude towards virtual education and its application is positive. Therefore, findings indicated there was a general positive attitude toward application of virtual education in university of pyam-e-noor Kurdistan. But, it requires more research to know which model of virtual education fits conditions and facilities in this university.

\section{References}

Creswell, J. W. (2003). Research design: qualitative, quantitative, and mixed approaches. California: Sage

Publications.

Daugherty, M., \& Funke, L. (1998). University Faculty and Student Perceptions of Web-Based Instruction. The

Journal of Distance Education, 13(1), 21-39. Retrieved from http://www.jofde.ca/index.php/jde/article/view/134/411

Hossein Mahdizadeh, Harm Biemans, \& Martin Mulder (2008). Determining factors of the use of e-learning environments by university teachers. Computers \& Education, 51, 142-154.

Keengwe, J., Onchwari, G., \& Onchwari, J. (2009). Technology and Student Learning: Towards a

Learner-Centered Teaching Model. AACE Journal, 17(1), 11-22. Chesapeake, VA: AACE. Retrieved from http://www.editlib.org/p/26258

Khalil Gholami, \& Yaser Sayadi1 (2012). The Facultys Perception of Web-based Instruction Application in Iran?s Higher Education. International Education Studies;, 5, 204-211.

Maguire, L. (2005). Literture review-Faculty participation in on line distance education: barriers and motivators.

Online Journal of Distance Learning Administration, VIII(I). Retrieved from http://www.westga.edu/ distance/ojdla/spring81/maguire81.htm

Muhannad Al-Shboul1 (2013). The Level of E-Learning Integration at the University of Jordan: Challenges and Opportunities. International Education Studies, 6.

Mobaraki, M. (2010). Examining learning condition in virtual education envoirnment: A case study of methodology course for educational sciences students; An MA thesis, Kurdistan Univrsity. Sanandaj, Iran.

Saiful Hafizah Jaaman, Rokiah Rozita Ahmad1, \& Azmin Sham Rambely1 (2013).

Web-Based Learning as a Tool of Knowledge Continuity. International Education Studies, 6. 
Sidney R. Castle, \& Chad J. McGuire (2010). An Analysis of Student Self-Assessment of Online, Blended, and Face-to-Face Learning Environments: Implications for Sustainable Education Delivery. International Education Studies, 3(19139020). UNESCO (2002). technology for education (1st ed.). UNESCO. UNESCO (2012). ICT IN EDUCATION IN LATIN AMERICA AND THE CARIBBEAN (1st ed.). Montreal, Quebec H3C 3J7 Canada: UNESCO Institute for Statistics.

Zarei, A. (2010). Examining faculty's attitudes of engineering faculty about applying technologies of web in

teaching and learning in Kurdistan University; An MA thesis, Far distance learning university. Tehran, Iran. 